\title{
ROTAS MICROFLUÍDICAS PARA A PRODUÇÃO DE LIPOSSOMAS DO TIPO STEALTH
}

\author{
G. PERLI ${ }^{1}$, A. C. S. N. PESSOA ${ }^{1}$, L. G. de LA TORRE ${ }^{1}$ \\ ${ }^{1}$ Universidade Estadual de Campinas, Faculdade de Engenharia Química, Departamento de \\ Engenharia de Materiais e Bioprocessos \\ E-mail para contato: latorre@feq.unicamp.br
}

RESUMO - A microfluídica é uma ciência e tecnologia que tem se apresentado como uma ferramenta importante na produção de micro e nanoestruturas, a partir do escoamento de pequenas quantidades de fluídos em dispositivos com dimensões bastante reduzidas. Dentre as nanoestruturas que podem ser produzidas, reporta-se na literatura a formação de lipossomas catiônicos através de plataformas de focalização hidrodinâmica, nas quais, a componente lipídica (em etanol) é injetada em um canal central sofrendo focalização lateral pela fase aquosa. O principal objetivo deste trabalho foi produzir lipossomas cationicos contendo polietilenoglicol (PEG) em dispositivo microfluídico. Para isso, foram investigadas duas estratégias: (1) promovendo a formação de lipossomas com PEG em apenas uma etapa e (2) a partir, da inserção posterior de lipídeo ligado ao PEG em lipossomas pré-formados. Quando produzidos através da primeira estratégia as nanoestruturas apresentaram 150,09 \pm $22,14 \mathrm{~nm}$ de diâmetro hidrodinâmico médio e $+63,00 \pm 7,03 \mathrm{mV}$ de potencial zeta. Como modelo padrão, realizou-se um estudo comparativo com métodos convencionais de produção (bulk), envolvendo a técnica de ultrassonicação. Nesse contexto, este trabalho visou contribuir com o desenvolvimento de processos microfluídicos de produção de lipossomas para aplicação em sistemas de liberação controlada de genes e fármacos.

\section{INTRODUÇÃO}

A terapia gênica é uma estratégia terapêutica que atua a partir da introdução de material genético às células-alvo, visando correção ou inativação dos genes responsáveis por uma patologia. Entretanto, devido ao tamanho, caráter aniônico e instabilidade química do material genético frente aos fluídos celulares, sua interiorização no núcleo celular (transfecção) é dificultada (Corsi et al., 2003).

A fim de aumentar a taxa de transfecção in vitro e in vivo, diversos sistemas de entrega controlada de ácidos nucleicos tem sido estudados. Dos quais, destacam-se os lipossomas catiônicos, cujas estruturas são aproximadamente esféricas e formadas a partir da autoagregação de lipídeos anfifílicos em lamelas. Devido ao seu caráter catiônico, esses lipossomas podem interagir eletrostaticamente com material genético (carregado negativamente), formando lipoplexos que apresentam aptidão para adentrar as células, em consequência da interação eletrostática dos lipoplexos com a membrana celular aniônica (Azzazy, Mansour e Kazmierczak, 2006).

Além do caráter catiônico, os lipossomas em questão apresentam boa compatibilidade e facilidade de modificação química de sua superfície, o que permite a produção de lipossomas 
ligados covalentemente a moléculas de PEG. Essa nova geração de lipossomas é conhecida como stealth e responsabilizam-se por aumentar significativamente o tempo de circulação desses nanocarreadores nos fluídos corporais (aquosos) (Ishida, Iden e Allen, 1999). Em vista disso, a otimização de processos para a produção desses nanocarreadores estabilizados com PEG se faz necessário.

Nesse contexto, a microfluídica emerge como uma técnica vantajosa para a produção de lipossomas de alto valor agregado, trabalhando com sistemas que processam pequenas quantidades de fluidos $\left(10^{-9}\right.$ a $10^{-18}$ litros), usando canais com dimensões de até centenas de micrômetros (Whitesides, 2006). Recentes avanços nesta ciência criaram novas perspectivas para as áreas de gene delivery.

Recentemente, nosso grupo de pesquisa mostrou a viabilidade do uso de técnicas microfluídicas para a produção de lipossomas catiônicos compostos por fosfatidilcolina de ovo (EPC), 1,2-dioleoil-sn-glicero-3-fosfoetanolamina (DOPE) e 1,2-dioleoil-3trimetilamôniopropano (DOTAP), através de dispositivos microfluídicos de focalização hidrodinâmica simples e dupla. No trabalho realizado por Balbino et al. (2016), os autores mostraram que os lipoplexos (lipossomas complexados com DNA) produzidos em dispositivos microfluídicos apresentaram maior capacidade de carreamento de material genético e maior eficiência de transfecção do que os lipoplexos produzidos por processos convencionais (mistura seguida de incubação).

Nesse contexto, o objetivo deste trabalho foi estudar duas estratégias de produção de lipossomas stealth em dispositivos microfluídicos, a fim de otimizar os processos de manufatura dessas nanoestruturas.

\section{MATERIAIS E MÉTODOS}

\subsection{Materiais}

Os lipossomas do tipo stealth foram produzidos com os lipídeos: 1,2-dioleoil-snglicero-3-fosfatidiletanolamina (DOPE), fosfatidilcolina natural de ovo (EPC), 1,2-dioleoil-3trimetilamônio-propano (DOTAP) e fosfolipídeo 1,2-diester-sn-glicero-3-fosfoetanolamina derivatizado com polietilenoglicol (MW 2000) (DSPE-PEG2000).

\subsection{Métodos}

Produção dos dispositivos: Utilizou-se a técnica de litografia macia em polidimetilsiloxano (PDMS), empregando Sylgard 184 Elastomer Kit da Dow Corning (Midland, MI, EUA), e selagem com lâmina de vidro através de plasma de $\mathrm{O}_{2}$. Esta etapa foi realizada no Centro Nacional de Pesquisa em Energia e Materiais - CNPEM.

Produção dos lipossomas: Inicialmente, os lipídeos foram dispersos em etanol anidro na concentração de $25 \mathrm{mM}$, nas proporções de EPC:DOPE:DOTAP iguais a 50:25:25, respectivamente. A produção de lipossomas foi realizada em concentração lipídica final de

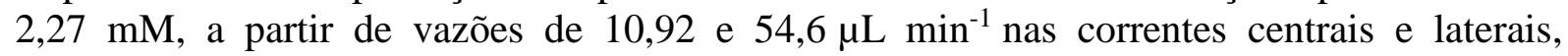
respectivamente. Para isso, empregaram-se bombas de seringas, modelo PHD2000 
(Infuse/Withdraw), da Harvard Apparatus. Os lipossomas funcionalizados com PEG foram produzidos a partir de duas estratégias diferentes: (a) inserindo todos os componentes lipídicos em uma entrada e (b) inserindo o DSPE-PEG (disperso em água) em uma segunda etapa, tal como apresentado na Figura 1(a) e 1(b). Os lipossomas com PEG utilizados como modelo foram produzidos a partir de um processo convencional (bulk), no qual a dispersão lipídica (suspensa em etanol anidro) é dispensada em excesso de água e a mistura é realizada através de ultrassonicação.

Figura 1 - Esquema ilustrativo de processo microfluídico de focalização hidrodinâmica utilizado na produção dos lipossomas pelas estratégias com (a) uma etapa e (b) duas etapas.

(a)
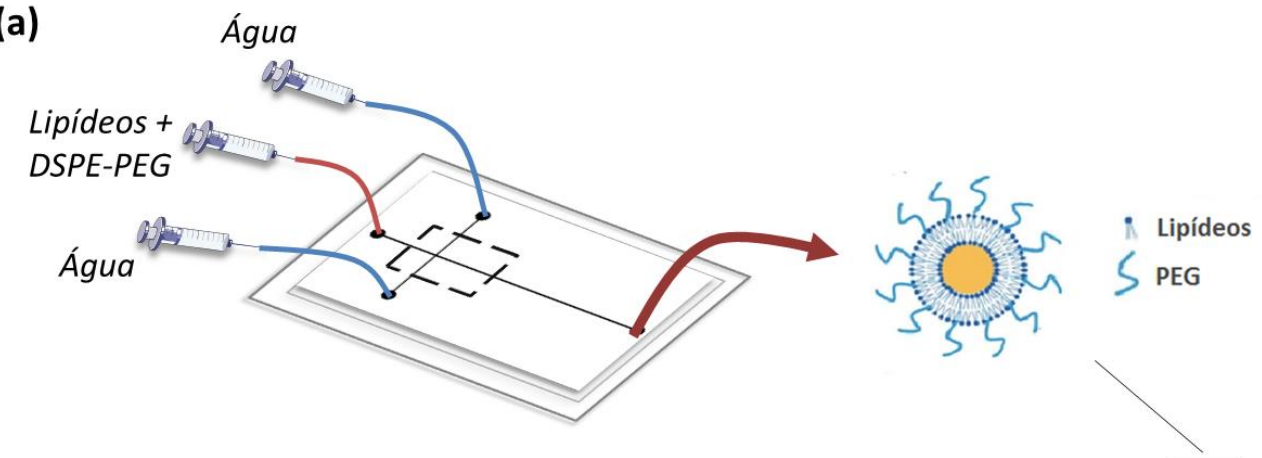

(b)

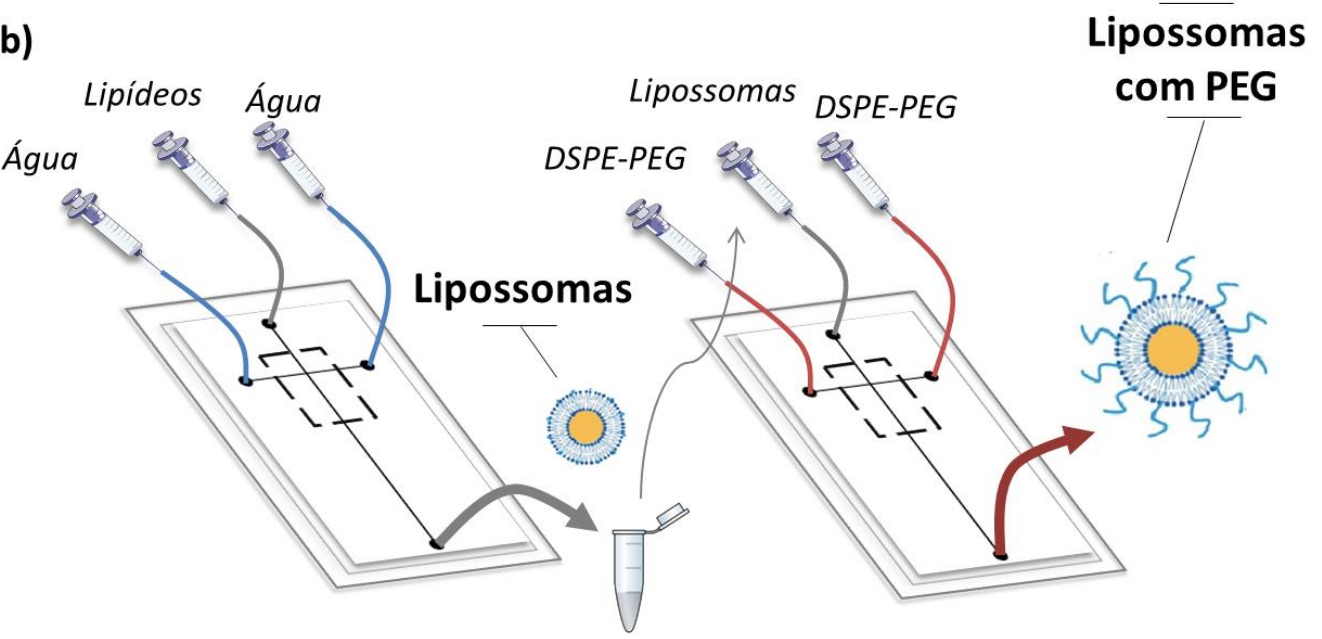

Caracterização físico-química das nanopartículas: As nanopartículas foram caracterizadas nos seguintes aspectos: diâmetro hidrodinâmico médio ponderado por intensidade, distribuição de tamanhos, índice de polidispersidade (PdI) e densidade superficial de carga (potencial zeta), utilizando equipamento Zetasizer Nano ZS da Malvern Instruments.

\section{RESULTADOS E DISCUSSÃO}

Em trabalhos anteriores de nosso grupo de pesquisa, lipossomas catiônicos foram produzidos com diâmetros hidrodinâmicos médios, polidispersidade e potencial zeta adequados para a aplicação em terapia gênica (Balbino et al., 2013). Em vista disso, neste trabalho, realizou-se um estudo exploratório para produção de lipossomas catiônicos, buscando-se em seguida estender o método utilizado para produzir lipossomas funcionalizados com PEG. 


\subsection{Produção de lipossomas}

Os lipossomas catiônicos foram sintetizados nas proporções de EPC:DOPE:DOTAP iguais a 50:25:25, empregando a plataforma microfluídica de focalização hidrodinâmica. A Tabela 1 apresenta a caracterização físico-química dos nanoagregados obtidos, para triplicatas independentes.

Tabela 1 - Diâmetro hidrodinâmico médio, polidispersidade e potencial zeta para lipossomas catiônicos produzidos em dispositivo microfluídico.

\begin{tabular}{clllllllll}
\hline Experimento & \multicolumn{3}{c}{ Diâmetro* $^{*} \mathbf{D P}^{* *}$} & \multicolumn{2}{c}{$\mathbf{P d I}^{*} \pm \mathbf{D P}^{* *}$} & \multicolumn{3}{c}{$\mathbf{P Z}^{*} \pm \mathbf{D P}^{* * *}$} \\
\hline 1 & 141,17 & \pm & 2,53 & 0,20 & \pm & 0,01 & 63,00 & \pm & 5,92 \\
\hline 2 & 143,27 & \pm & 2,03 & 0,18 & \pm & 0,02 & 63,30 & \pm & 8,44 \\
\hline 3 & 137,43 & \pm & 1,00 & 0,15 & \pm & 0,02 & 65,90 & \pm & 1,03 \\
\hline Média & $\mathbf{1 4 0 , 6 2}$ & \pm & $\mathbf{1 , 8 5}$ & $\mathbf{0 , 1 8}$ & \pm & $\mathbf{0 , 0 1}$ & $\mathbf{6 4 , 0 6}$ & \pm & $\mathbf{5 , 1 3}$
\end{tabular}

* Diâmetro equivale a diâmetro hidrodinâmico médio, PdI a índice de polidispersidade e PZ a potencial zeta. ${ }^{* *}$ DP corresponde ao desvio padrão de triplicatas independentes.

Com base nos resultados apresentados na Tabela 1, os lipossomas catiônicos apresentaram diâmetros hidrodinâmicos, polidispersidade e potencial zeta ideais para testes in vitro, com elevada capacidade de serem internalizados pelas células (Honary e Zahir, 2013). Esses resultados motivaram a investigação da produção de lipossomas do tipo stealth para aplicações futuras como nanocarreadores de genes e fármacos.

\subsection{Produção de lipossomas funcionalizados com PEG}

Em seguida, lipossomas com PEG foram produzidos através das estratégias (a) com apenas uma etapa de formação dos nanocarreadores e (b) em duas etapas, com inserção subsequente de DSPE-PEG nos lipossomas pré-formados (Figura 1(a) e 1(b)). Para isso, utilizou-se os lipídeos EPC:DOPE:DOTAP:DSPE-PEG nas proporções molares 50:20:25:5, respectivamente, correspondendo a 5\% de porcentagem molar de DSPE-PEG.

O método convencional de produção de lipossomas (bulk) com ultrassonicação foi utilizado como modelo comparativo, por ser uma metodologia já conhecida, permitindo a formação de lipossomas com boas características físico-químicas. No entanto, trata-se de um processo dispendioso, susceptível à experiência do operador e que depende da uniformidade da mistura para garantir a reprodutibilidade do processo (Lu et al., 2014). Os resultados deste estudo comparativo estão apresentados graficamente na Figura 2(a) e 2(b).

Comparando-se os resultados de diâmetro médio obtidos pelos três métodos, pode-se afirmar que o valor obtido para a estratégia com apenas uma etapa apresentou alta correlação com o resultado apresentado pelo método bulk, sendo o erro relativo de $1,7 \%$. No entanto, o procedimento de inserção posterior de DSPE-PEG nos lipossomas pré-formados (duas etapas), não apresentou resultado satisfatório, de modo que, o erro relativo para a medida de diâmetro foi de $63,5 \%$. Tal erro, provavelmente está relacionado à formação de micelas formadas essencialmente de DSPE-PEG (cuja cadeia de polietilenoglicol possui $2 \mathrm{kDa}$ ). Lujan e Alamos (2004) afirmam que as micelas formadas a partir da macromolécula em questão, 


\section{Congresso Brasileiro de Engenharia Química em Iniciação Científica UFSCar - São Carlos - SP 16 a 19 de Julho de 2017}

apresentam diâmetros de $17 \mathrm{~nm}$, o que diminuiria sensivelmente o raio hidrodinâmico médio dos lipossomas produzidos.

Figura 2 - Valores de (a) diâmetro hidrodinâmico médio, polidispersidade e (b) potencial zeta para lipossomas catiônicos com PEG (5\%) produzidos a partir de três metodologias diferentes. As barras de erro correspondem ao desvio padrão de triplicatas independentes.

(a)

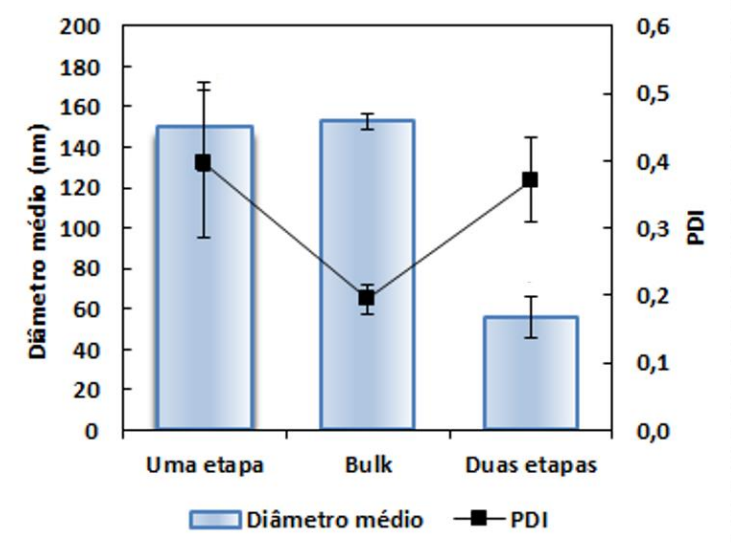

(b)

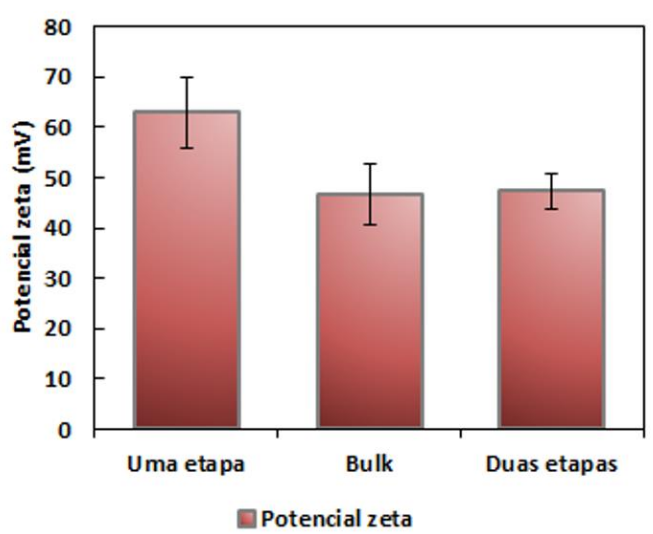

Em vista disso, pode-se inferir que, quando preparados pelo método de duas etapas, o lipídeo DSPE-PEG pode não ter sido inserido adequadamente na bicamada lipídica dos lipossomas pré-formados. Essa hipótese é suportada pela análise do perfil de distribuição de diâmetro médio (Figura 3(a) e 3(b)), na qual é evidente a existência de duas populações quando a estratégia de inserção subsequente de DSPE-PEG é aplicada para produzir as nanopartículas.

Figura 3 - Perfil de distribuição de tamanho ponderado por intensidade para lipossomas catiônicos com PEG (5\%) produzidos em (a) uma etapa e (b) duas etapas.

(a)

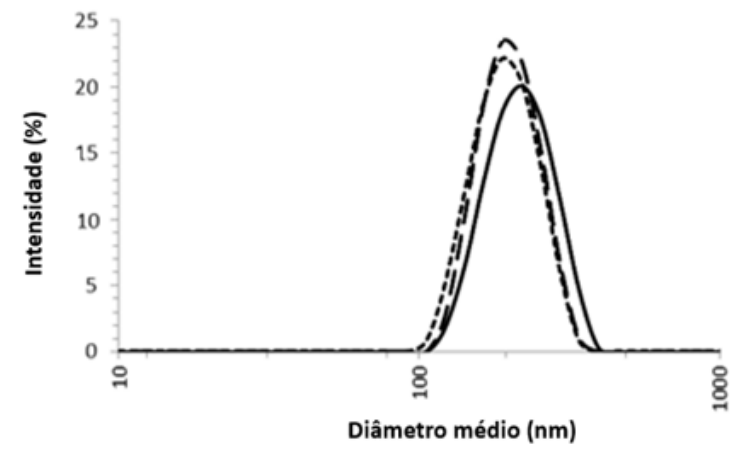

(b)

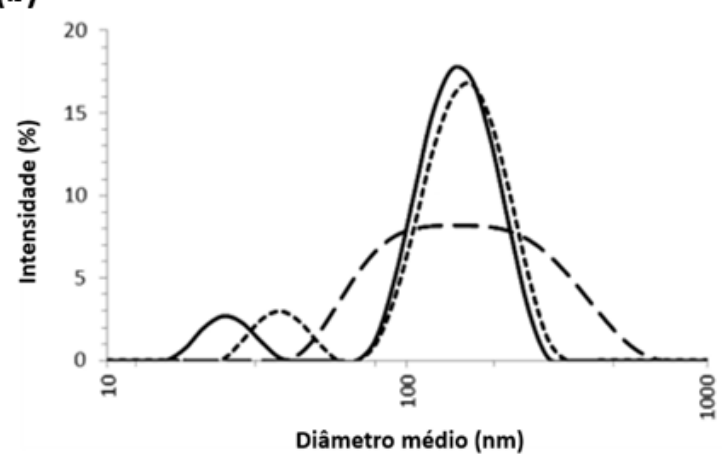

Comparando-se os índices de polidispersidade dos lipossomas produzidos a partir das duas estratégias microfluídicas (Figura 2 (a)), não se verifica diferença expressiva entre os valores encontrados. No entanto, considerando os perfis de distribuição de tamanho (Figura 3(a) e 3(b)), constata-se caráter unimodal apenas para os lipossomas produzidos empregando o método microfluídico com uma etapa. 
Para os valores de potencial zeta, os lipossomas produzidos em microfluídica em duas etapas apresentou boa correspondência com o modelo padrão, sendo o erro relativo de aproximadamente $1 \%$, enquanto o método em uma etapa apresentaram menor correlação com os valores relativos a produção bulk (erro relativo de 35\%). Entretanto, o valor encontrado é característico de sistemas coloidais estáveis e capazes de aumentar a transfecção celular (Honary e Zahir, 2013).

\section{CONCLUSÃO}

Pela análise dos resultados obtidos para diâmetro hidrodinâmico médio, polidispersidade e potencial zeta, pode-se observar que os lipossomas produzidos possuem características adequadas para ensaios biológicos. A comparação entre as duas rotas de produção de lipossomas do tipo stealth em dispositivo microfluídico, permitiu concluir que a formação das nanopartículas em uma etapa apresentou-se mais vantajosa em termos de processo e características dos lipossomas, quando comparada a rota microfluídica em duas etapas.

\section{REFERÊNCIAS}

AZZAZY, H. M. E.; MANSOUR, M. M. H.; KAZMIERCZAK, S. C. Nanodiagnostics: A new frontier for clinical laboratory medicine. Clin. Chem., v. 52, n. 7, p. 1238-1246, 2006.

BALBINO, T. A. et al. Continuous flow production of cationic liposomes at high lipid concentration in microfluidic devices for gene delivery applications. Chem. Eng. J., v. 226, p. 423-433, 2013.

BALBINO, T. A. et al. Microfluidic Assembly of pDNA/Cationic Liposome Lipoplexes with High pDNA Loading for Gene Delivery. Langmuir, v. 32, n. 7, p. 1799-1807, 2016.

CORSI, K. et al. Mesenchymal stem cells, MG63 and HEK293 transfection using chitosanDNA nanoparticles. Biomaterials, v. 24, n. 7, p. 1255-1264, 2003.

HONARY, S.; ZAHIR, F. Effect of Zeta Potential on the Properties of Nano-Drug Delivery Systems - A Review ( Part 2 ). v. 12, n. April, p. 265-273, 2013.

ISHIDA, T.; IDEN, D. L.; ALLEN, T. M. A combinatorial approach to producing sterically stabilized (Stealth) immunoliposomal drugs. FEBS Lett., v. 460, n. 1, p. 129-133, 1999.

LU, M. et al. Three-dimensional hydrodynamic focusing method for polyplex synthesis. ACS Nano, v. 8, n. 1, p. 332-339, 2014.

LUJAN, M.; ALAMOS, L. In Vitro Characterization of PEGylated Phospholipid Micelles for Improved Drug Solubilization : Effects of PEG Chain Length and PC Incorporation. v. 93, n. 10, p. 2476-2487, 2004.

WHITESIDES, G. M. The origins and the future of microfluidics. Nature, v. 442, n. 7101, p. 368-373, 2006. 